\title{
Effect of BDNF on airway inflammation in a rat model of COPD
}

\author{
ZHENGLI GUO $^{1,2}$, LEI LIU ${ }^{2}$, SHASHA LI ${ }^{3}$, BINGQING XU ${ }^{2}$, \\ YIHUI $\mathrm{XU}^{2}$ and HUIPING $\mathrm{LI}^{4}$ \\ ${ }^{1}$ Medical College, Soochow University, Suzhou, Jiangsu 215031; ${ }^{2}$ Department of Geriatrics; \\ ${ }^{3}$ Clinical Research and Lab Center, Affiliated Kunshan Hospital of Jiangsu University, Kunshan, Jiangsu 215300; \\ ${ }^{4}$ Department of Respiratory and Critical Care Medicine, Shanghai Pulmonary Hospital, \\ School of Medicine, Tongji University, Shanghai 200433, P.R. China
}

Received February 22, 2020; Accepted July 2, 2021

DOI: $10.3892 / \mathrm{etm} .2021 .10550$

\begin{abstract}
Chronic obstructive pulmonary disease (COPD) is characterized by airflow limitation that is not fully reversible. The airflow limitation is usually progressive and associated with an abnormal inflammatory response of the lungs to noxious particles or gases. The present study aimed to investigate the effect of brain-derived neurotrophic factor (BDNF) on lung function and airway inflammation in a rat model of COPD. A rat model of COPD was established in this study, and anti-BDNF antibody was injected to observe the effect of BDNF on pulmonary function and airway inflammation. Lung function and hematoxylin and eosin staining analyses were performed. BDNF in the airway was examined using immunohistochemistry, western blotting and enzyme-linked immunosorbent assay. Levels of oxidant stress and inflammatory cytokines were measured. After long-term heavy cigarette exposure, pulmonary inflammation and emphysema were observed, while lung function had deteriorated in the COPD, COPD + anti-BDNF and COPD + normal saline groups. Levels of BDNF expression, malondialdehyde, tumor necrosis factor- $\alpha$ and interleukin- 6 were increased in rats with COPD compared with control rats, while levels of superoxide dismutase and glutathione peroxidase were decreased. Anti-BDNF intervention improved airway inflammation. To conclude, anti-BDNF intervention could alleviate inflammation and improve any imbalance between oxidation and antioxidation in the airway.
\end{abstract}

\section{Introduction}

Chronic obstructive pulmonary disease (COPD) is a type of pulmonary disease characterized by airflow restriction that is

Correspondence to: Dr Huiping Li, Department of Respiratory and Critical Care Medicine, Shanghai Pulmonary Hospital, School of Medicine, Tongji University, 507 Zheng Min Road, Shanghai 200433, P.R. China

E-mail: liw2013@126.com

Key words: chronic obstructive pulmonary disease, brain-derived neurotrophic factor, airway, oxidant stress largely irreversible and a progressive course (1). According to the World Health Organization, COPD will become the third deadliest disease worldwide by 2030 , and is projected to affect an increasingly large proportion of the global population $(2,3)$. Airway inflammation and remodeling are major types of structural and functional changes in COPD, which contribute to exaggerated airway narrowing and resistance to airflow (4). Air pollution, tobacco exposure and repeated respiratory tract infection lead to persistent lung inflammation, which eventually causes deterioration of lung function (1).

Airway smooth muscle and the mucous membrane receive sensory innervation, and the sensory terminals can release a series of regulatory factors (e.g. neurotrophic factors) (5). Brain-derived neurotrophic factor (BDNF) is a major member of the neurotrophic factor family, which also plays an important role in the regulation of airway neurogenic inflammation (6). BDNF is a key neuroprotective factor that promotes and maintains the survival of sensory neurons, and the growth of neurites (7). BDNF can be produced by and act on immune inflammatory cells (8). Moreover, the levels of BDNF are increased in inflammatory, autoimmune and allergic diseases, such as asthma and allergic rhinitis (9).

Although its presence in the nervous system is well-known (10), BDNF is also expressed by structural cells of the lung. Thus, it has the potential to influence airway structure and function $(11,12)$. For example, sputum and bronchoalveolar lavage fluid from patients with asthma show increased levels of $\operatorname{BDNF}(13,14)$. Previous studies regarding the effect of BDNF on the airway mainly focused on asthma and airway inflammation after viral infection (15-17). Few studies have focused on the role of BDNF in COPD-related airway inflammation. Thus, the aim of the present study was to investigate the effect of BDNF on pulmonary function and airway inflammation in a rat model of COPD.

\section{Materials and methods}

Animals and models. A total of 28 male Sprague-Dawley rats (age, 6-8 weeks; weight, 180-200 g) were obtained from Shanghai Sipper-BK Laboratory Animal Co. All animal experiments and procedures were approved (approval nos. AS20180042GZL and 20180213) by the Animal Care and Use Committee of the Affiliated Kunshan Hospital of Jiangsu University (Kunshan, 
China). They were performed in accordance with the Guide for the Care and Use of Laboratory Animals, published by the United States National Institutes of Health (18). All animals were fed in a silent environment at $18-25^{\circ} \mathrm{C}$ (relative humidity, 40-70\%), housed away from bright light under a 10/14 h day/night cycle, and given free access to food and water. The rats were acclimated for 1 week before the experiments. The animals were divided into control, COPD, COPD + anti-BDNF and COPD + normal saline (NS) groups ( $\mathrm{n}=7$ rats per group).

Rats in the COPD, COPD + anti-BDNF and COPD + NS groups were exposed to cigarette smoke (Hongmei cigarettes; $13 \mathrm{mg} \mathrm{CO} ; 13 \mathrm{mg}$ tar oil) for $30 \mathrm{~min} /$ day, twice per day at 6-h intervals. This treatment was performed 6 days per week for 16 weeks in an $8050^{\mathrm{TM}}$ inhalation exposure system (Tianjin Hope Industry \& Trade Co., Ltd.) (19). Rats in the COPD + anti-BDNF and COPD + NS groups were intraperitoneally injected with anti-BDNF antibody $(1: 1,000 ; 0.1 \mathrm{~g} / \mathrm{ml} ; 4 \mathrm{ml} / \mathrm{kg}$; cat. no. ab108319; Abcam) and NS (4 ml/kg), respectively, once per week for 4 consecutive weeks. The experimental procedure is shown in Fig. 1.

Lung function. Lung function was assessed based on the ratio of forced expiratory volume $(\mathrm{FEV})$ at $0.2 \mathrm{sec}\left(\mathrm{FEV}_{0.2}\right)$ to forced vital capacity (FVC), as well as the peak expiratory flow (PEF) (20). Rats were injected with $1 \%$ pentobarbital sodium (40 mg/kg, intraperitoneal injection), and then administered with appropriate anesthetics for the maintenance of anesthesia. The trachea of each rat was cut, intubated, and attached to a ventilator at a respiratory rate of 75 beats $/ \mathrm{min}$ with a tidal volume of $5 \mathrm{ml} / \mathrm{kg}$. The $\mathrm{FEV}_{0.2} / \mathrm{FVC}$ and PEF were measured using the AniRes2005 pulmonary mechanics analyzer (Beijing Bestlab High-Tech).

Specimen processing. After lung function measurements were performed, rats were anesthetized with $1 \%$ pentobarbital sodium (40 mg/kg, intraperitoneal injection), and subsequently transcardially perfused with $0.3 \%$ PBS. Lung and bronchial tissues were rapidly removed. Left lung tissue was sectioned at $5 \mu \mathrm{m}$ for $\mathrm{H} \& \mathrm{E}$ staining, immunohistochemistry and western blotting. Right lung tissue was used for enzyme-linked immunosorbent assay and detection of oxidative stress.

$H \& E$ staining. Lung tissues were fixed in $10 \%$ neutral formalin for $24 \mathrm{~h}$ at room temperature and subsequently paraffin-embedded. Sections $(5 \mu \mathrm{m})$ were prepared from the paraffin-embedded tissue blocks by dehydration through a graded ethanol series $(75,85,95$ and $100 \%)$ and washed with xylene. Sections were stained with H\&E for $12 \mathrm{~min}$ at room temperature. Morphological changes in the lung tissues were evaluated using an Olympus light microscope (magnification, x400; Olympus Corporation).

Immunohistochemistry. Lung tissues were frozen with optimal cutting temperature compound (cat. no. ZLI9302; ZSBIO Co.) and coronally sectioned using a Leica freezing microtome (Leica Microsystems, Inc.). Lung tissue sections were incubated with $3 \% \mathrm{H}_{2} \mathrm{O}_{2}$ for 15 min to block endogenous peroxidase activity, washed with $0.3 \%$ PBS $(3 \times 5 \mathrm{~min})$, incubated for $1 \mathrm{~h}$ at room temperature with a blocking solution $(10 \%$ goat serum; cat. no. ZLI9022; ZSBIO Co.), and then incubated at $4^{\circ} \mathrm{C}$ overnight with the primary antibody (rabbit anti-BDNF; 1:1,000; cat. no. ab108319; Abcam). Tissue sections were washed with $0.3 \%$ PBS ( $3 \times 5 \mathrm{~min})$ and then incubated for $1 \mathrm{~h}$ at room temperature with a biotinylated secondary antibody (goat anti-rabbit; 1:500; cat. no. ab6721; Abcam). After tissue sections had been washed with $0.3 \%$ PBS $(3 \times 5 \mathrm{~min})$, they were incubated for $30 \mathrm{~min}$ with avidin/biotinylated horseradish peroxidase, washed with $0.3 \%$ PBS $(3 \times 5 \mathrm{~min})$, and reacted with DAB as a chromogen. Sections were observed using an Olympus light microscope (Olympus Corporation).

Enzyme-linked immunosorbent assay. The bronchi and lungs were weighed, boiled $\left(100^{\circ} \mathrm{C}\right)$ for $10 \mathrm{~min}$ in $1 \mathrm{M}$ acetic acid (1:10, wt/vol), suspended in 0.1 M PBS, and homogenized. Homogenates were transferred to polypropylene tubes and centrifuged (40,000 x g, $\left.4^{\circ} \mathrm{C}, 20 \mathrm{~min}\right)$. Before measurements were taken, the supernatant was centrifuged again at 40,000 $\mathrm{x} g$ and $4^{\circ} \mathrm{C}$ for $20 \mathrm{~min}$. BDNF (cat. no. DBNT00; R\&D Systems, Inc.), IL-6 and TNF- $\alpha$ (cat. no. 31857; Cayman Chemical Company) concentrations were measured using enzyme-linked immunosorbent assay kits, according to the manufacturer's instructions.

Western blotting. Lung samples were placed in lysis buffer containing protease inhibitors, and then homogenized and centrifuged at $15,000 \mathrm{x}$ g and $4^{\circ} \mathrm{C}$ for $10 \mathrm{~min}$. Protein concentrations were measured using a BCA protein assay kit. A total of $50 \mu \mathrm{g}$ total protein was separated via 10\% SDS-PAGE gel electrophoresis, and then transferred by electroblotting onto PVDF membranes. The membranes were blocked at room temperature with 3\% BSA (cat. no. 9998; CST Biological Reagents Co., Ltd.) in TBS containing $0.1 \%$ Tween-20 for $1 \mathrm{~h}$, and then incubated overnight at $4^{\circ} \mathrm{C}$ with the primary antibody rabbit, anti-BDNF (1:500; cat. no. ab108319; Abcam). The membranes were then washed with TBS containing $0.1 \%$ Tween-20 and incubated for $1 \mathrm{~h}$ at room temperature with a horseradish peroxidase-conjugated secondary antibody (1:2,000; cat. no. 31461; Invitrogen; Thermo Fisher Scientific, Inc.). Protein bands were detected using an ECL substrate kit (cat. no. WP20005; Invitrogen; Thermo Fisher Scientific, Inc.) and then exposed to CL-XPosure film (Pierce; Thermo Fisher Scientific, Inc.). GAPDH (1:4,000; cat. no. 9545; Sigma-Aldrich; Merck KGaA) was used as the internal control.

Oxidant stress detection. The levels of malondialdehyde (MDA; cat. no. A003-1-2), glutathione peroxidase (GSH; cat. no. A005-1-2) and superoxide dismutase (SOD; cat. no. A001-3-2) were measured in the lung tissues using appropriate kits (Nanjing Jiancheng Bioengineering Institute).

Statistical analysis. All experiments were performed in triplicate. Data are expressed as the mean \pm standard deviation and were analyzed using SPSS software (17.0; SPSS Inc.). Comparisons among multiple groups were performed using one-way analysis of variance, followed by Tukey's post hoc test. $\mathrm{P}<0.05$ was considered to indicate a statistically significant difference.

\section{Results}

Lung functions and histological changes. Smoking is a major risk factor for the development of COPD. In the control 


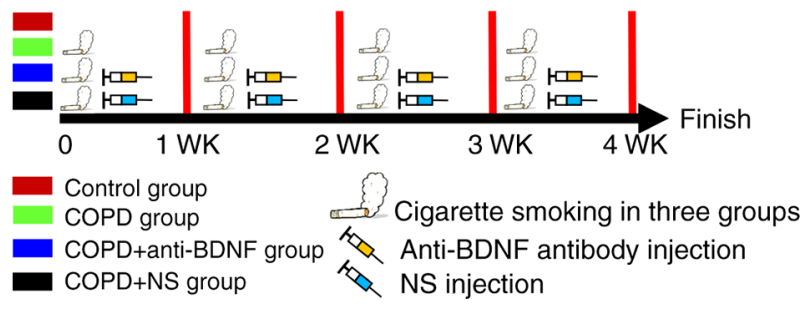

Figure 1. Experimental protocol. Rats in the COPD, COPD + anti-BDNF and COPD + NS groups were exposed to cigarette smoke for 4 weeks Rats in the COPD + anti-BDNF group were injected intraperitoneally with anti-BDNF antibody $(1: 1,000,0.1 \mathrm{~g} / \mathrm{ml}, 4 \mathrm{ml} / \mathrm{kg})$ once per week for 4 consecutive weeks, while rats in the COPD + NS group were injected with $\mathrm{NS}(4 \mathrm{ml} / \mathrm{kg}) . \mathrm{n}=7$ rats per group. COPD, chronic obstructive pulmonary disease; BDNF, brain-derived neurotrophic factor; NS, normal saline.

group, the bronchial mucosa was normal and the alveoli were uniform. In the COPD group, the bronchial mucosa epithelium was necrotic and showed exfoliation with infiltrating inflammatory cells (mainly neutrophils and macrophages). The alveoli were of different sizes, and their walls were thinned and broken, as some had fused to form pulmonary bullae. Anti-BDNF treatment alleviated the inflammation compared with the COPD group (Fig. 2A and B). After long-term heavy cigarette exposure, the $\mathrm{FEV}_{0.2} / \mathrm{FVC}$ and $\mathrm{PEF}$ values in rats with COPD were reduced significantly compared with control rats $(\mathrm{P}<0.01)$. However, there were no differences between rats in the COPD group and those in the COPD + anti-BDNF or COPD + NS groups ( $>>0.05$; Fig. $2 \mathrm{C})$. These results indicated that anti-BDNF intervention did not affect lung function or histopathological findings.

BDNF expression in the airway. BDNF-like immunoreactivity (red arrow) was indicated by brown staining of bronchial and lung tissues, predominantly in the cytoplasm of epithelial cells in the peribronchial region (Fig. 3A). The BDNF expression level measured by western blotting was significantly increased in the COPD group compared with the control group $(\mathrm{P}<0.01)$. However, this level was decreased in the COPD + anti-BDNF group compared with the COPD group $(\mathrm{P}<0.01)$. BDNF expression did not significantly differ between the COPD and COPD + NS groups ( $\mathrm{P}>0.05$; Fig. 3B). BDNF concentrations measured by enzyme-linked immunosorbent assay showed similar results. The BDNF concentration was higher in the COPD group than in the control group $(\mathrm{P}<0.01)$. Conversely, the BDNF concentration was lower in the COPD + anti-BDNF group than in the COPD group $(\mathrm{P}<0.05)$. The BDNF concentration did not significantly differ between the COPD and COPD $+\mathrm{NS}$ groups $(\mathrm{P}>0.05$; Fig. $3 \mathrm{C})$. These results indicated that anti-BDNF antibody injection could reduce BDNF expression level in the airway.

Oxidative stress in the airway. Long-term cigarette smoking induces oxidative stress (21). Therefore, the levels of MDA, SOD and GSH in the airway and lung were measured. After cigarette smoke exposure, the level of MDA was significantly increased in the COPD group compared with the control group $(\mathrm{P}<0.01)$, and was significantly decreased in the COPD + anti-BDNF group compared with the COPD group $(\mathrm{P}<0.01)$. The MDA level did not significantly differ between the COPD and COPD + NS groups ( $\mathrm{P}>0.05$; Fig. 4A). By contrast, the levels of SOD and GSH were significantly decreased in the COPD group compared with the control group (both $\mathrm{P}<0.01$ ), and were increased in the COPD + anti-BDNF group compared with the COPD group (both $\mathrm{P}<0.01$ ). The SOD and GSH levels did not significantly differ between the COPD and COPD + NS groups (both $\mathrm{P}>0.05$; Fig. 4B and C). These data demonstrated that anti-BDNF could improve the imbalance of oxidation and antioxidation in the airway and lung.

Pro-inflammatory cytokines in the airway. Inflammation is an important component of COPD pathogenesis (22). In this study, levels of the representative inflammatory markers TNF- $\alpha$ and IL- 6 were examined. The levels of both markers were significantly increased in the COPD group compared with the control group (both $\mathrm{P}<0.01$ ). However, the levels of these markers were decreased in the COPD + anti-BDNF group compared with the COPD group $(\mathrm{P}<0.05$ and $\mathrm{P}<0.01$, respectively). The levels of TNF- $\alpha$ and IL- 6 did not significantly differ between the COPD group and the COPD + NS group (both $\mathrm{P}>0.05$; Fig. $5 \mathrm{~A}$ and $\mathrm{B}$ ). These results indicated that anti-BDNF treatment could alleviate smoking-induced airway inflammation.

\section{Discussion}

COPD is a common respiratory disease characterized by progressive and irreversible airway obstruction. Because of the long course of disease, repeated episodes, delays, exacerbation and reduced quality of life, patients with COPD often experience anxiety and depression (23). BDNF is a protein synthesized in the brain and then widely distributed in the central nervous system. BDNF plays an important role in the survival, differentiation, and growth of neurons (24). Notably, it can prevent neurons from being damaged and undergoing apoptosis, in addition to promoting the regeneration and differentiation of damaged neurons (25). Therefore, BDNF is an important target of antidepressant treatment $(26,27)$.

Previous studies have reported that BDNF is closely associated with multiple pulmonary diseases (28-31). BDNF has shown an association with allergic airway inflammation, especially asthma (32). Air pollutant exposure is a risk factor for the development of allergic diseases and respiratory infections (33). Active smoking and secondhand smoke can both potentiate the effects of other allergens. In a mouse model of allergic asthma, BDNF contributed to airway hyperreactivity and allergic inflammation (16). Airway BDNF secretion is regulated at multiple levels, thus influencing airway contractility and remodeling (29,34). Specific BDNF gene polymorphisms may contribute to bronchial asthma susceptibility, and a positive association between selected functional BDNF polymorphisms (i.e., rs6265) and asthma has been suggested in children (35).

However, to the best of our knowledge, there have been few studies regarding the relationship between BDNF expression and airway inflammation in patients with COPD. In the present study, the effects of anti-BDNF treatment on airway inflammation and lung function in a rat model of COPD were explored. The results indicated that cigarette smoking could induce BDNF expression in the airway. Although anti-BDNF 
A

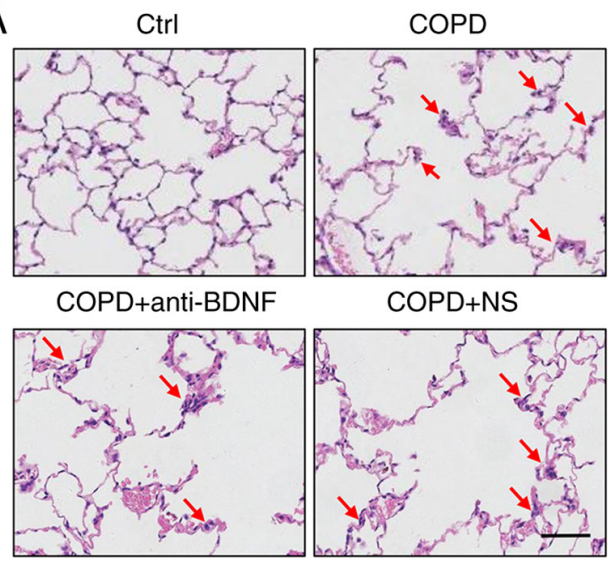

B
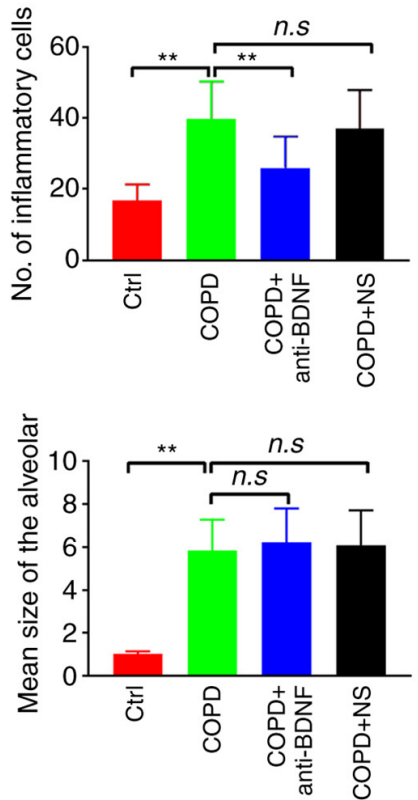

C
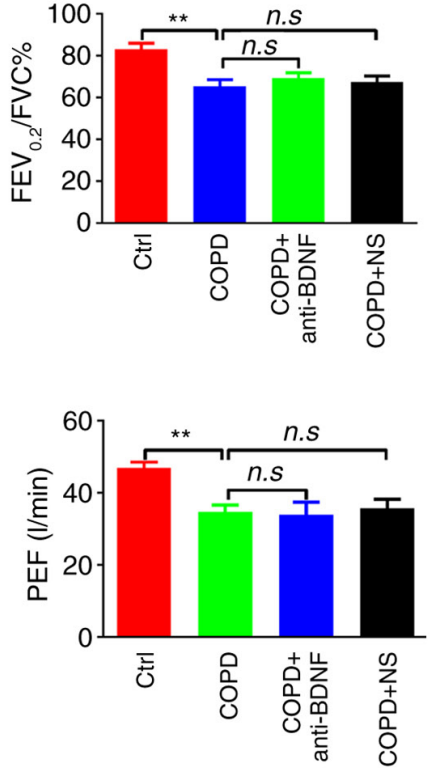

Figure 2. Effect of anti-BDNF treatment on airway inflammation and lung function. (A) Histological changes observed in the lung tissues. Inflammatory cells were marked by red arrows. In the control group, the alveoli exhibited uniform size, and there was no obvious inflammatory cell infiltration in the airway. In the COPD group, the bronchial mucosa epithelium was necrotic and exhibited exfoliation with infiltrating inflammatory cells. Additionally, multiple alveoli were fused to form pulmonary bullae. In the COPD + anti-BDNF group, inflammatory cells in the airway were slightly reduced compared with the COPD group, but alveolar fusion was similar to that observed in the COPD group. Pulmonary histopathological changes in the COPD + NS group were similar to those in the COPD group. Scale bar, $200 \mu \mathrm{m}$. (B) Numbers of inflammatory cells and mean size of alveoli. Cigarette smoke inhalation may cause airway inflammation, emphysema and inflammatory cell infiltration of bronchial tissue. The numbers of inflammatory cells were greater in the COPD group than in the control group. When rats were treated with anti-BDNF antibody, the number of inflammatory cells was significantly lower than that in the COPD group. There were no significant differences between the COPD + anti-BDNF and COPD + NS groups. The alveolar space was markedly dilated in the COPD, COPD + anti-BDNF and COPD + NS groups, indicating that anti-BDNF antibody treatment did not improve emphysema. (C) Lung functions. After cigarette smoke exposure, lung function indices $\left(\mathrm{FEV}_{02} / \mathrm{FVC} \%\right.$ and $\left.\mathrm{PEF}\right)$ were significantly decreased compared with the control group. Anti-BDNF antibody and $\mathrm{NS}$ injection both caused no significant changes in the COPD + anti-BDNF or COPD + NS group relative to the COPD group. $n=7$ rats per group. ${ }^{* *} \mathrm{P}<0.01$ vs. COPD group. $\mathrm{COPD}$, chronic obstructive pulmonary disease; $\mathrm{BDNF}$, brain-derived neurotrophic factor; $\mathrm{NS}$, normal saline; $\mathrm{FEV}_{0.2}$, forced expiratory volume at 0.2 sec; $\mathrm{FVC}$, forced vital capacity; PEF, peak expiratory flow.

A

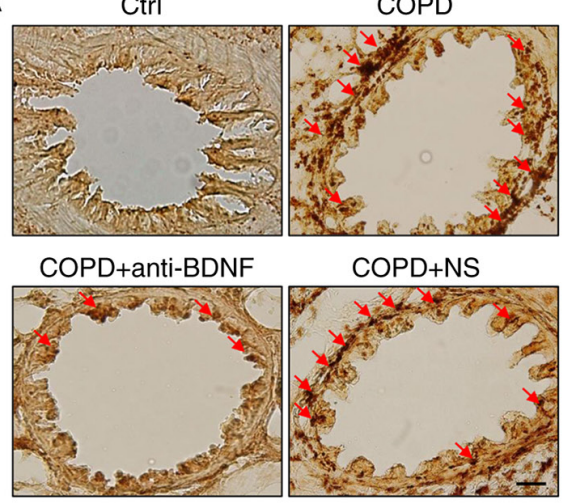

B

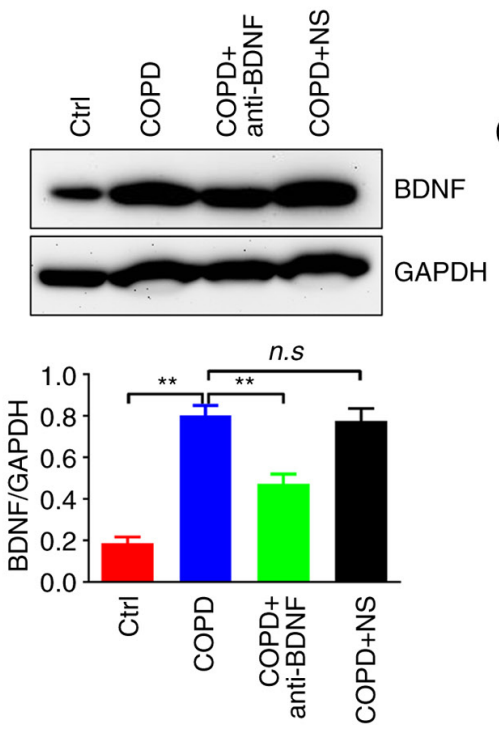

C

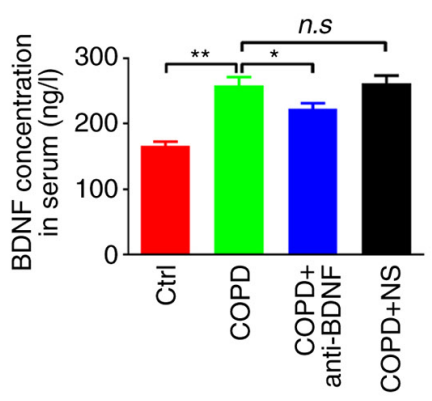

Figure 3. BDNF expression levels in the lung. (A) Immunohistochemistry of BDNF expression levels (brown staining, red arrow) in the airway. In the COPD group, the BDNF expression level was significantly increased compared with the control group, whereas it was decreased in the COPD + anti-BDNF group. In the COPD + NS group, the BDNF expression level was similar to that in the COPD group. BDNF-like immunoreactivity was indicated by brown staining in bronchi and lung tissues, predominantly in the cytoplasm of epithelial cells in the peribronchial region. Scale bar, $100 \mu \mathrm{m}$. (B) Western blotting of BDNF expression in the airway. Similar to the immunohistochemistry findings, BDNF expression, as detected by western blotting, was increased in the COPD group compared with the control group. The ratio of BDNF/GAPDH was near 0.8 in the COPD group (vs. 0.2 in the control group), but decreased in the COPD + anti-BDNF group BDNF expression did not differ between the COPD + anti-BDNF and COPD + NS groups. (C) Enzyme-linked immunosorbent assay measurement of BDNF concentrations. The BDNF concentration was higher in the COPD group than in the control group, but decreased upon treatment with anti-BDNF antibody. The BDNF concentration did not differ between the COPD + anti-BDNF and COPD + NS groups. $\mathrm{n}=7$ rats per group. ${ }^{*} \mathrm{P}<0.05,{ }^{* *} \mathrm{P}<0.01$ vs. COPD group. COPD, chronic obstructive pulmonary disease; BDNF, brain-derived neurotrophic factor; NS, normal saline. 
A

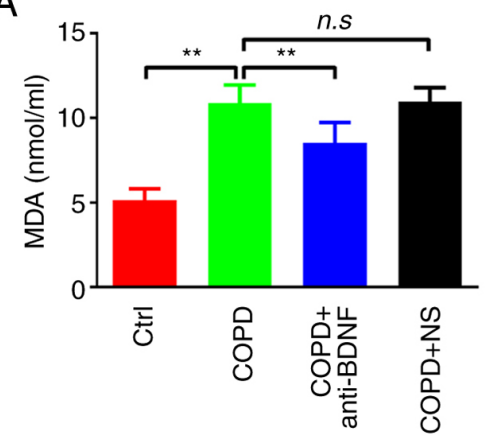

B

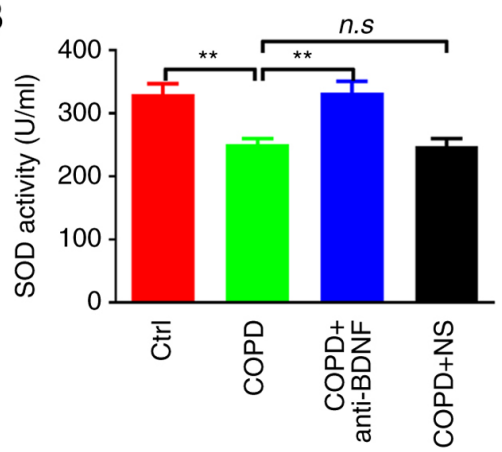

C

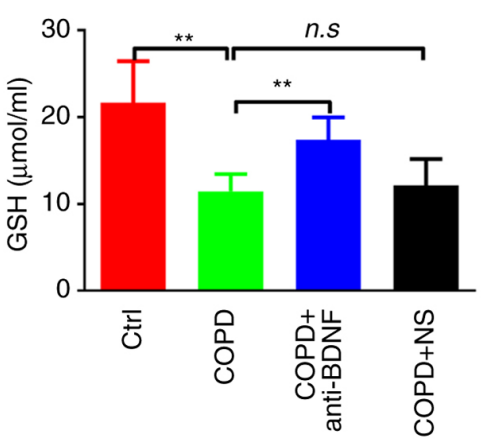

Figure 4. Effect of anti-BDNF treatment on oxidative stress. Levels of (A) MDA, (B) SOD and (C) GSH. Cigarette smoke exposure may induce an imbalance between oxidation and antioxidation in the airway. The level of MDA was increased, whereas those of SOD and GSH were decreased, in the COPD group compared with the control group. After anti-BDNF antibody administration, the levels of MDA, SOD and GSH were improved. There was no difference in the MDA, SOD or GSH level between the COPD and COPD + NS groups. $\mathrm{n}=7$ rats per group. ${ }^{* *} \mathrm{P}<0.01$ vs. COPD group. MDA, malondialdehyde; GSH, glutathione peroxidase; SOD, superoxide dismutase; COPD, chronic obstructive pulmonary disease; BDNF, brain-derived neurotrophic factor; NS, normal saline.

treatment did not improve lung function in rats with COPD, the inflammatory cytokine levels and imbalance between oxidation and antioxidation in the airway were alleviated. Regarding the underlying mechanism, increased BDNF may promote airway irritability via the nervous system, modulate epithelium-derived bronchodilator responses, or increase airway smooth muscle $\left[\mathrm{Ca}^{2+}\right]_{\mathrm{i}}$ and contractility, especially in the presence of inflammatory cytokines (36). BDNF may modulate airway remodeling via proliferation, migration, and secretion of inflammatory mediators and modulators (37). Furthermore, BDNF secretion is controlled by nerves. As a growth factor, BDNF (potentially derived from local tissues or nerves themselves) can enhance the survival or expansion of receptive fields of sensory nerve endings (38). Importantly, increased BDNF expression and secretion by airway smooth muscle in the inflamed airway may act on postganglionic parasympathetic airway nerves (39). Given that neuronal activity itself can enhance BDNF expression and release, a positive feedback cycle may be established in the disease state, which would promote nerve expansion (40). BDNF can also enhance the expression levels of other receptors, and synaptic transmission, thereby enhancing bronchoconstriction $(41,42)$. In patients with COPD, abnormal activity of the vagal nerve innervating the airway may lead to increased secretion of BDNF and further aggravation of airway inflammation, thus affecting respiratory function (17). However, in the present study, anti-BDNF treatment did not improve lung function in the experimental rats. This may be related to the short-duration cigarette smoke exposure. Therefore, further experiments are needed with longer smoke exposure to confirm whether BDNF has an effect on lung function.

There are a number of limitations to the present study. Smoke exposure is a key causative factor of COPD, however, alternative factors, such as environmental pollution and infection may also impact the pathophysiological process of COPD. Thus, further investigation into the role of anti-BDNF treatment in the improvement of airway inflammation in COPD induced by fine particulate matter exposure or respiratory infection is required.

In conclusion, this study showed that cigarette smoke exposure could lead to increased BDNF expression levels in the airway of rats with COPD. Thus, BDNF may be related to airway inflammation. Anti-BDNF treatment could alleviate
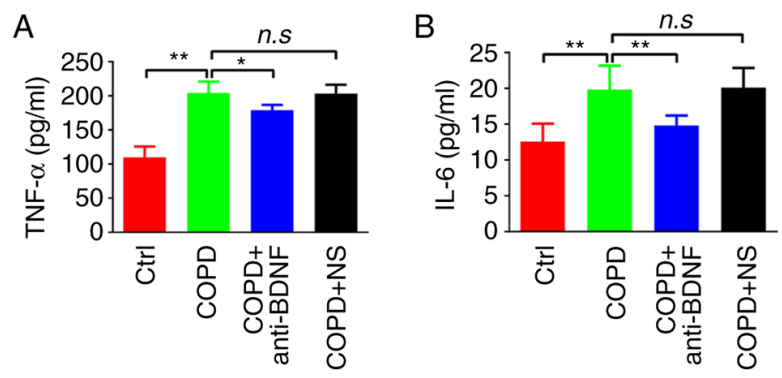

Figure 5. Effect of anti-BDNF treatment on pro-inflammatory cytokines. Levels of (A) TNF- $\alpha$ and (B) IL-6. Cigarette smoking exposure may induce airway inflammation. Levels of TNF- $\alpha$ and IL- 6 were increased in the COPD group compared with the control group. The levels decreased after anti-BDNF antibody administration compared with the COPD group. There was no difference in the TNF- $\alpha$ or IL-6 level between the COPD and COPD + NS groups. $\mathrm{n}=7$ rats per group. ${ }^{*} \mathrm{P}<0.05,{ }^{* *} \mathrm{P}<0.01$ vs. COPD group. $\mathrm{COPD}$, chronic obstructive pulmonary disease; BDNF, brain-derived neurotrophic factor; NS, normal saline; IL-6, interleukin-6; TNF- $\alpha$ tumor, necrosis factor- $\alpha$.

airway inflammation and improve the imbalance between oxidation and antioxidation in the airway.

\section{Acknowledgements}

Not applicable.

\section{Funding}

The present study was supported by grants from the Kunshan Science Project (grant no. KS1723) and Jiangsu University (grant no. JLY2021068).

\section{Availability of data and materials}

The datasets used and/or analyzed during the current study are available from the corresponding author on reasonable request.

\section{Authors' contributions}

ZG, SL and BX were responsible for performing the experiments and writing the manuscript. LL and YX were 
responsible for designing the study, performing the experiments and collecting the data. HL was responsible for providing experimental ideas, data analysis, interpretation of data and reviewing the manuscript. ZG and HL confirm the authenticity of all the raw data. All authors have read and approved the final manuscript.

\section{Ethics approval and consent to participate}

All animal experiments and procedures were approved (approval nos. AS20180042GZL and 20180213) by the Animal Care and Use Committee of the Affiliated Kunshan Hospital of Jiangsu University (Kunshan, China). They were performed in accordance with the Guide for the Care and Use of Laboratory Animals, published by the United States National Institutes of Health.

\section{Patient consent for publication}

Not applicable.

\section{Competing interests}

The authors declare that they have no competing interests.

\section{References}

1. Lareau SC, Fahy B, Meek P and Wang A: Chronic obstructive pulmonary disease (COPD). Am J Respir Crit Care Med 199: P1-P2, 2019.

2. López-Campos JL, Tan W and Soriano JB: Global burden of COPD. Respirology 21: 14-23, 2016.

3. Mathers CD and Loncar D: Projections of global mortality and burden of disease from 2002 to 2030. PLoS Med 3: e442, 2006.

4. Barnes PJ: Inflammatory endotypes in COPD. Allergy 74: 1249-1256, 2019

5. Mazzone SB and Undem BJ: Vagal afferent innervation of the airways in health and disease. Physiol Rev 96: 975-1024, 2016.

6. Bennedich Kahn L, Gustafsson LE and Olgart Höglund C: Brain-derived neurotrophic factor enhances histamine-induced airway responses and changes levels of exhaled nitric oxide in guinea pigs in vivo. Eur J Pharmacol 595: 78-83, 2008.

7. Lu B, Nagappan G and Lu Y: BDNF and synaptic plasticity, cognitive function, and dysfunction. Handb Exp Pharmacol 220: 223-250, 2014

8. Hahn C, Islamian AP, Renz H and Nockher WA: Airway epithelial cells produce neurotrophins and promote the survival of eosinophils during allergic airway inflammation. J Allergy Clin Immunol 117: 787-794, 2006.

9. Raap U and Braunstahl GJ: The role of neurotrophins in the pathophysiology of allergic rhinitis. Curr Opin Allergy Clin Immunol 10: 8-13, 2010.

10. Hempstead BL: Brain-derived neurotrophic factor: Three ligands, many actions. Trans Am Clin Climatol Assoc 126: 9-19, 2015.

11. Prakash Y, Thompson MA, Meuchel L, Pabelick CM, Mantilla CB, Zaidi S and Martin RJ: Neurotrophins in lung health and disease. Expert Rev Respir Med 4: 395-411, 2010.

12. Watanabe T, Fajt ML, Trudeau JB, Voraphani N, Hu H, Zhou X, Holguin F and Wenzel SE: Brain-derived neurotrophic factor expression in asthma. Association with severity and type 2 inflammatory processes. Am J Respir Cell Mol Biol 53: 844-852, 2015

13. Braun A, Lommatzsch M, Mannsfeldt A, Neuhaus-Steinmetz U, Fischer A, Schnoy N, Lewin GR and Renz H: Cellular sources of enhanced brain-derived neurotrophic factor production in a mouse model of allergic inflammation. Am J Respir Cell Mol Biol 21: 537-546, 1999.

14. Virchow JC, Julius P, Lommatzsch M, Luttmann W, Renz H and Braun A: Neurotrophins are increased in bronchoalveolar lavage fluid after segmental allergen provocation. Am J Respir Crit Care Med 158: 2002-2005, 1998 .
15. Zang N, Li S, Li W, Xie X, Ren L, Long X, Xie J, Deng Y, Fu Z, Xu F and Liu E: Resveratrol suppresses persistent airway inflammation and hyperresponsivess might partially via nerve growth factor in respiratory syncytial virus-infected mice. Int Immunopharmacol 28: 121-128, 2015.

16. Britt RD Jr, Thompson MA, Wicher SA, Manlove LJ, Roesler A, Fang YH, Roos C, Smith L, Miller JD, Pabelick CM and Prakash YS: Smooth muscle brain-derived neurotrophic factor contributes to airway hyperreactivity in a mouse model of allergic asthma. FASEB J 33: 3024-3034, 2019.

17. Papp C, Pak K, Erdei T, Juhasz B, Seres I, Szentpéteri A, Kardos L, Szilasi M, Gesztelyi R and Zsuga J: Alteration of the irisin-brain-derived neurotrophic factor axis contributes to disturbance of mood in COPD patients. Int J Chron Obstruct Pulmon Dis 12: 2023-2033, 2017.

18. Guide for the Care and Use of Laboratory Animals. Washington (DC). National Academies Press (US), 1996.

19. Lin L, Yin Y, Hou G, Han D, Kang J and Wang Q: Ursolic acid attenuates cigarette smoke-induced emphysema in rats by regulating PERK and Nrf2 pathways. Pulm Pharmacol Ther 44: 111-121, 2017.

20. Yu N, Sun YT, Su XM, He M, Dai B and Kang J: Treatment with eucalyptol mitigates cigarette smoke-induced lung injury through suppressing ICAM-1 gene expression. Biosci Rep: Jul 6 , 2018 (Epub ahead of print). doi: 10.1042/BSR20171636.

21. Hikichi M, Mizumura K, Maruoka S and Gon Y: Pathogenesis of chronic obstructive pulmonary disease (COPD) induced by cigarette smoke. J Thorac Dis 11: (Suppl 17): S2129-S2140, 2019.

22. Rabe KF and Watz H: Chronic obstructive pulmonary disease. Lancet 389: 1931-1940, 2017

23. Yohannes AM and Alexopoulos GS: Depression and anxiety in patients with COPD. Eur Respir Rev 23: 345-349, 2014.

24. Binder DK and Scharfman HE: Brain-derived neurotrophic factor. Growth Factors 22: 123-131, 2004

25. Wang H, Zhao Y, Wang YJ, Song L, Wang JL, Huang C, Zhang W and Jiang B: Antidepressant-like effects of tetrahydroxystilbene glucoside in mice: Involvement of BDNF signaling cascade in the hippocampus. CNS Neurosci Ther 23: 627-636, 2017.

26. Brunoni AR, Baeken C, Machado-Vieira R, Gattaz WF and Vanderhasselt MA: BDNF blood levels after non-invasive brain stimulation interventions in major depressive disorder: A systematic review and meta-analysis. World J Biol Psychiatry 16: 114-122, 2015.

27. Tuon T, Valvassori SS, Dal Pont GC, Paganini CS, Pozzi BG, Luciano TF, Souza PS, Quevedo J, Souza CT and Pinho RA: Physical training prevents depressive symptoms and a decrease in brain-derived neurotrophic factor in Parkinson's disease. Brain Res Bull 108: 106-112, 2014.

28. Lieu T and Undem BJ: Neuroplasticity in vagal afferent neurons involved in cough. Pulm Pharmacol Ther 24: 276-279, 2011

29. Freeman MR, Sathish V, Manlove L, Wang S, Britt RD Jr, Thompson MA, Pabelick CM and Prakash YS: Brain-derived neurotrophic factor and airway fibrosis in asthma. Am J Physiol Lung Cell Mol Physiol 313: L360-L370, 2017.

30. Zhang SY, Hui LP, Li CY, Gao J, Cui ZS and Qiu XS: More expression of BDNF associates with lung squamous cell carcinoma and is critical to the proliferation and invasion of lung cancer cells. BMC Cancer 16: 171, 2016.

31. Yao Q, Zaidi SI, Haxhiu MA and Martin RJ: Neonatal lung and airway injury: A role for neurotrophins. Semin Perinatol 30: 156-162, 2006

32. Nassenstein C, Braun A, Erpenbeck VJ, Lommatzsch M, Schmidt S, Krug N, Luttmann W, Renz H and Virchow JC Jr: The neurotrophins nerve growth factor, brain-derived neurotrophic factor, neurotrophin-3, and neurotrophin-4 are survival and activation factors for eosinophils in patients with allergic bronchial asthma. J Exp Med 198: 455-467, 2003.

33. Brauer M, Hoek G, Smit HA, de Jongste JC, Gerritsen J, Postma DS, Kerkhof $\mathrm{M}$ and Brunekreef B: Air pollution and development of asthma, allergy and infections in a birth cohort. Eur Respir J 29: 879-888, 2007.

34. Aravamudan B, Thompson MA, Pabelick CM and Prakash YS: Mechanisms of BDNF regulation in asthmatic airway smooth muscle. Am J Physiol Lung Cell Mol Physiol 311: L270-L279, 2016.

35. Jesenak M, Babusikova E, Evinova A, Banovcin P and Dobrota D: Val66Met polymorphism in the BDNF gene in children with bronchial asthma. Pediatr Pulmonol 50: 631-637, 2015.

36. Prakash YS, Thompson MA and Pabelick CM: Brain-derived neurotrophic factor in TNF-alpha modulation of $\mathrm{Ca}^{2+}$ in human airway smooth muscle. Am J Respir Cell Mol Biol 41: 603-611, 2009. 
37. Bai TR: Evidence for airway remodeling in chronic asthma. Curr Opin Allergy Clin Immunol 10: 82-86, 2010.

38. Numakawa T, Suzuki S, Kumamaru E, Adachi N, Richards M and Kunugi $\mathrm{H}$ : BDNF function and intracellular signaling in neurons. Histol Histopathol 25: 237-258, 2010.

39. Pan J, Rhode HK, Undem BJ and Myers AC: Neurotransmitters in airway parasympathetic neurons altered by neurotrophin-3 and repeated allergen challenge. Am J Respir Cell Mol Biol 43: 452-457, 2010.

40. Park H and Poo MM: Neurotrophin regulation of neural circuit development and function. Nat Rev Neurosci 14: 7-23, 2013.
41. Meuchel LW, Stewart A, Smelter DF, Abcejo AJ, Thompson MA, Zaidi SI, Martin RJ and Prakash YS: Neurokinin-neurotrophin interactions in airway smooth muscle. Am J Physiol Lung Cell Mol Physiol 301: L91-L98, 2011.

42. Piedimonte G: Contribution of neuroimmune mechanisms to airway inflammation and remodeling during and after respiratory syncytial virus infection. Pediatr Infect Dis J22 (Suppl2): S66-S75, 2003.

This work is licensed under a Creative Commons Attribution-NonCommercial-NoDerivatives 4.0 International (CC BY-NC-ND 4.0) License. 